Article

\title{
Simulating an Autonomously Operating Low-Cost Static Terrestrial LiDAR for Multitemporal Maize Crop Height Measurements
}

\author{
Sophie Crommelinck ${ }^{1}$ and Bernhard Höfle ${ }^{1,2, *}$ \\ 1 GIScience Research Group, Institute of Geography, Heidelberg University, Heidelberg 69120, Germany; \\ crommelinck@stud.uni-heidelberg.de \\ 2 Heidelberg Center for the Environment (HCE), Heidelberg University, Heidelberg 69120, Germany \\ * Correspondence: hoefle@uni-heidelberg.de; Tel.: +49-6221-54-5594; Fax: +49-6221-54-4529
}

Academic Editors: Mutlu Ozdogan, Yoshio Inoue and Prasad S. Thenkabail

Received: 30 November 2015; Accepted: 25 February 2016; Published: 2 March 2016

\begin{abstract}
In order to optimize agricultural processes, near real-time spatial information about in-field variations, such as crop height development (i.e., changes over time), is indispensable. This development can be captured with a LiDAR system. However, its applicability in precision agriculture is often hindered due to high costs and unstandardized processing methods. This study investigates the potential of an autonomously operating low-cost static terrestrial laser scanner (TLS) for multitemporal height monitoring of maize crops. A low-cost system is simulated by artificially reducing the point density of data captured during eight different campaigns. The data were used to derive and assess crop height models (CHM). Results show that heights calculated with CHM based on the unreduced point cloud are accurate when compared to manually measured heights (mean deviation $=0.02 \mathrm{~m}$, standard deviation $=0.15 \mathrm{~m}$, root mean square error $($ RMSE $)=0.16 \mathrm{~m})$. When reducing the point cloud to $2 \%$ of its original size to simulate a low-cost system, this difference increases (mean deviation $=0.12 \mathrm{~m}$, standard deviation $=0.19 \mathrm{~m}$, RMSE $=0.22 \mathrm{~m}$ ). We found that applying the simulated low-cost TLS system in precision agriculture is possible with acceptable accuracy up to an angular scan resolution of $8 \mathrm{mrad}$ (i.e., point spacing of $80 \mathrm{~mm}$ at $10 \mathrm{~m}$ distance). General guidelines for the measurement set-up and an automatically executable method for CHM generation and assessment are provided and deserve consideration in further studies.
\end{abstract}

Keywords: precision agriculture; multitemporal; low-cost LiDAR; ATLS; crop monitoring; crop surface models

\section{Introduction}

Light detection and ranging (LiDAR) has emerged as a powerful active remote sensing method for direct measurement of 3D plant structure in precision agriculture [1,2]. The importance of 3D geodata in agriculture lies in its usability for plant modeling and plant-specific parameterization to monitor and improve crop management strategies [1,2]. Applications include fertilization, irrigation management, yield estimation and optimization of harvesting processes [3]. LiDAR data can, e.g., be used to adjust height settings for agricultural machines to crop surface [4]. These applications, which consider costs and resources while reducing harm to the environment, aim to make agricultural production more effective as the application of fertilizer, pesticides and irrigation is optimized [5].

Complexities caused by the outdoor agricultural environment, such as variable natural lighting, occlusion and obscuration of plant features by foliage from neighboring plants [6] make an automatic observation of in-field variations challenging. This has led to the use of different remote sensing technologies to capture in-field variations including ultrasonic sensors [7-11], photography [12-14], 
stereo images [15-18], light sensors [19], high-resolution radar images [20,21] and high-resolution X-ray computed tomography [22]. A detailed description and review of sensing technologies used in precision agriculture can be found in $[1,3,6]$.

These methods often pose practical problems in field conditions since they have a limited ability to describe a crop's 3D structure in a fast, repeatable, and accurate way [23]. In contrast, terrestrial laser scanning (TLS) provides a tool for generating a unique and comprehensive quantitative description of 3D plant and crop structure. Processing and analysis of TLS data have already been automated for phenotyping plants [24,25] and for classification of vegetation types [26]. The majority of crop-vegetation related studies based on TLS measurements deal with forest crop structure [27]. Research on TLS on agricultural crops includes studies on maize [28,29], cereals [30], tomatoes [31], fruit-trees [32] and vineyards [11,33]. In these studies, TLS is used to measure in-field variations of crop development by characterizing its 3D structure.

Crop height is an important parameter for local assessment and monitoring of crop types such as maize and wheat $[28,34,35]$. The growth rate responds to nutrients, water, and temperature [36] and can be used as an indicator for external conditions of soil, weather, irrigation and fertilization. Growth rate is mostly correlated with the crop's biomass [37-39] and variety as well as the plant's nutrient content.

The parameter crop height, as well as entire plant and foliage structures, can be captured with a TLS [36]. A TLS system acquires multitemporal data such as crop height development when operating constantly and autonomously. Such scanning systems can be emulated by mounting a laser rangefinder on a pan tilt unit, which automatically carries out horizontal and vertical scanning by rotating within predefined angles. This set-up represents a simplified version of a laser scanner, which is realizable at a low-cost compared to commonly used high-end TLS systems. Such an autonomously operating TLS (ATLS) was first designed and investigated by Eitel et al. in 2013 for use in forestry applications [40] and later by Culvenor et al. in 2014 [41]. These ATLS systems automatically capture multitemporal vegetation development, which adds time information to the 3D point cloud.

This study aims to identify specific requirements for a robust sensing system with automatically manageable data to improve precision agriculture applications. This is done by simulating a low-cost stationary TLS, which collects multitemporal crop height data. A workflow for processing and assessing ATLS data is developed. The workflow extracts the crop height development of maize by deriving crop height models (CHM), which represent the spatial crop growth pattern on a field level [42]. The specific outcomes of this study are: (a) clear requirements for a static ATLS system commendable for its successful use in precision agriculture; and (b) a point cloud processing workflow for multitemporal monitoring of maize's crop height.

\section{Materials and Methods}

\subsection{Study Area and Measurement Set-Up}

A maize field in Heidelberg, Germany $\left(49.43430^{\circ} \mathrm{N}, 8.65466^{\circ} \mathrm{E}\right.$, WGS84) served as the study area. The maize data were captured eight times over a period of 75 days starting on 28 May 2015 and ending on 10 August 2015. The measurements were conducted 40, 66, 75, 95, 100, 107 and 114 days after seeding, which took place on 18 April 2015. The observed growth stages ranged from the vegetative to the reproductive stage. The field had an area of $2.5 \mathrm{ha}$, from which a study area of approximately 1.5 ha $(165 \mathrm{~m} \times 90 \mathrm{~m})$ was selected.

For scanning maize crops a time-of-flight scanner VZ-400 (Riegl, Horn, Austria) [43] with full-waveform online echo detection was used (Figure 1). The system applies a near-infrared $(1550 \mathrm{~nm})$ laser beam with a beam divergence of $0.3 \mathrm{mrad}$ and a range accuracy of $5 \mathrm{~mm}$ (one sigma) at $100 \mathrm{~m}$. The system was installed on a water barrel located at one edge of the field (Figure 2). The barrel was filled with $1000 \mathrm{~L}$ of water in order to keep it in the same position for the entirety of the study. The set-up raised the sensor to a height of $3.6 \mathrm{~m}$. This single scan position was used to simulate and 
determine the most cost-effective solution in terms of scan resolution and point spacing. Installation of each further scan position would raise the cost of the entire system and thus only one scan position for permanent monitoring was applied in our investigation.

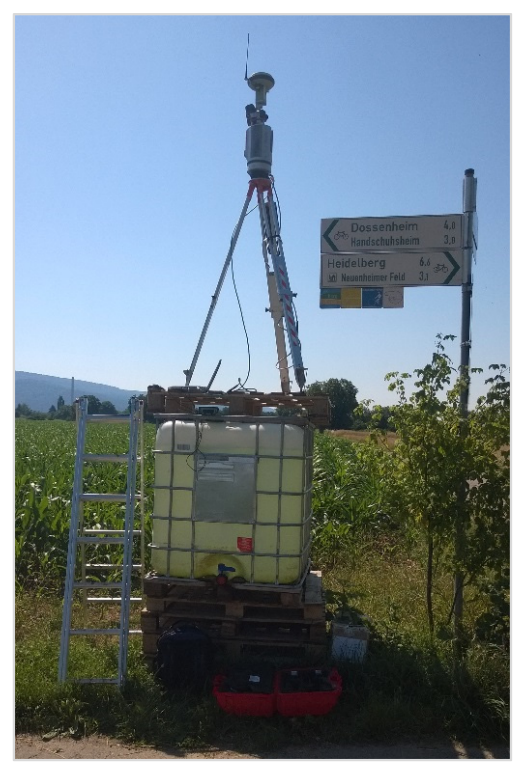

Figure 1. Scanner set up on barrel for elevated scanning at a height of $3.6 \mathrm{~m}$, located at one edge of the monitored maize field.

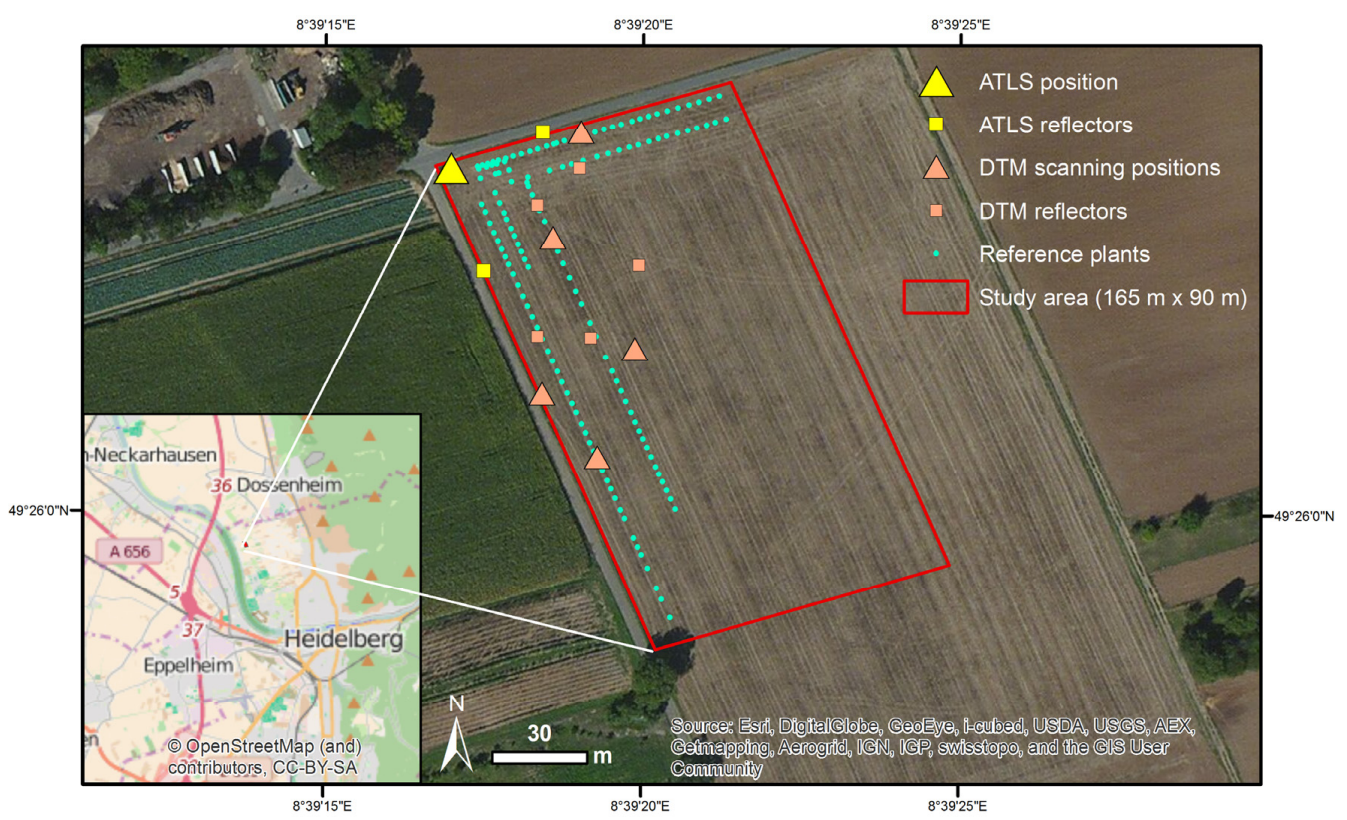

Figure 2. Overview of measurement set-up located in Heidelberg (Germany) for simulation of autonomously operating terrestrial laser scanner (ATLS) for multiple campaigns $\left(t_{1}-t_{8}\right)$ and for capturing data to generate a digital terrain model (DTM) of the first campaign $\left(t_{1}\right)$.

Using a single, static position for the simulated ATLS system has the additional advantage of not requiring the establishment of a reference target network. This is generally necessary to register multitemporal TLS scans to one common coordinate system. Therefore, the set-up should ideally be realized at one fixed position. Changing the scanner's position during each campaign might require a GNSS receiver to determine its accurate position in a global coordinate system, increasing costs 
and processing time for data registration. However, in this study, the scanner was registered to a global coordinate system in each scan campaign, since it could not be precluded that the simulated ATLS system would not change in position between measurements, as it had to be reinstalled for each measurement. To accurately register the ATLS position, a real time kinematic (RTK) GNSS base (Leica GS10) with a coordinate quality, on average, of $0.01 \mathrm{~m}$ was installed before each measurement on a known unchanging position. A RTK GNSS rover (Leica GS15) then captured the accurate position of the scanner.

Furthermore, two positions at the side of the field were chosen to set up tie point reflectors. They consisted of a signal pole mounted with a reflecting cylinder of known size and were placed where they were visible by the scanner even when the maize was very tall [42]. They were fastened to metal poles that were secured about $30 \mathrm{~cm}$ into the ground. This allowed the re-establishment of the reflectors at the same position for each measurement. To verify this, the accurate position of the reflectors was measured with an RTK GNSS rover. In addition, the height and position of 140 plants along different transects in the field were measured manually with a measuring tape and a RTK GNSS rover each time. The manually measured height is defined in this study as the maximum plant height above the location of one of the 140 reference plants, which were georeferenced with the RTK GNSS rover. If a leaf of a neighboring plant was located above the reference plant, then this was measured as reference crop height for that specific location.

An overview of the measurement set-up is provided in Figure 2. Since the first campaign $\left(t_{1}\right)$ aimed to gain data for a complete high-resolution digital terrain model (DTM), multiple scanning positions and reflectors were used. For the subsequent set-up of the simulated ATLS system $\left(t_{2}-t_{8}\right)$, only one scan position and two reflectors were used.

\subsection{Generation of Crop Height Models}

A crop surface model (CSM) represents the upper boundary of a crop field as an elevation value introduced by Hoffmeister et al. [42] for deriving spatial crop growth patterns on a field level. A crop height model (CHM) represents the crop height by subtracting the DTM value from the maximum CSM elevation value per cell. The workflow of CHM generation is shown in Figure 3. Our workflow aims to extract multitemporal CHMs of maize crops based on TLS measurements of different point densities. From TLS data of the first campaign $\left(t_{1}\right)$, a DTM for the study area was extracted. TLS data for each campaign $\left(t_{1}-t_{8}\right)$ were captured and registered to a common coordinate system. Then, point density was systematically decimated by keeping every $n^{\text {th }}$ emitted laser beam according to its timestamp with increasing step width $n$ as proposed by Hämmerle et al. [4]. This allows the simulation of ATLS systems with different scanning capabilities in terms of point density. From these datasets, CHMs were derived by calculating the difference between CSM per campaign $\left(t_{1}-t_{8}\right)$ and DTM from the first campaign $\left(t_{1}\right)$.

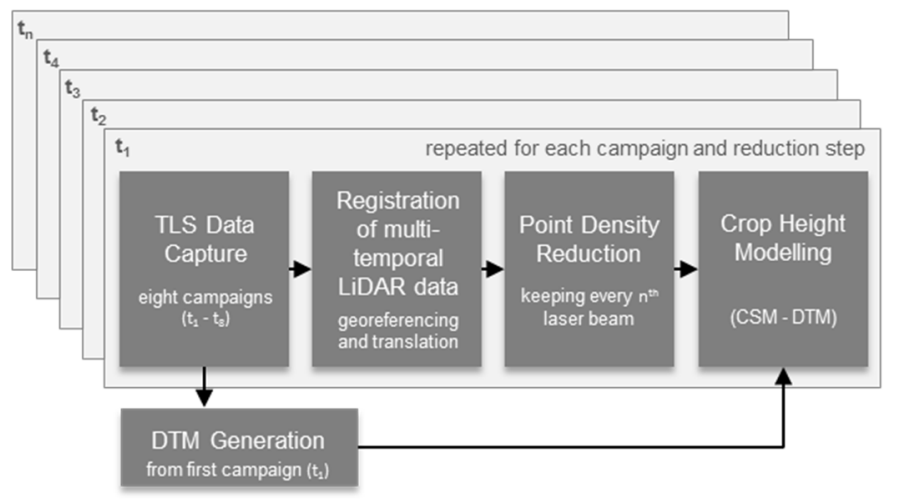

Figure 3. Workflow of crop height model (CHM) generation from the capture of terrestrial laser scan (TLS) data to CHMs calculation from reduced point density data sets. 
For raster calculations, a cell size of $0.25 \mathrm{~m} \times 0.25 \mathrm{~m}$ was determined based on the spatial plant distribution in the field; i.e., how the seeds were placed. Due to a distance of $15 \mathrm{~cm}$ between plants and $70 \mathrm{~cm}$ between plant rows, increasing the cell size (i.e., larger cells) would lead to including more than one plant in a cell. Making the cells finer (i.e., smaller) would lead to the fact that sub-parts of a plant are represented in the cells.

\subsubsection{DTM Generation}

The DTM was generated from TLS data acquired at the first measurement campaign on 28 May when the maize was $0.23 \mathrm{~m}$ high, on average, according to 140 manual measurements. The last fertilization process with a tractor driving on the field and changing the field's surface was on 27 May. Therefore, our acquisition time guarantees a DTM usable as a constant basis for further calculations. Six scan positions and seven tie point reflectors were used (Figure 2). Due to the use of multiple scan positions, the ground was captured effectively, despite minor occlusion effects from the small maize crops. A point cloud based terrain filter for removal of vegetation from RiSCAN Pro [44] automatically differentiated between off-terrain and terrain points. This classification utilizes distances between points and the estimated ground surface based on a grid representation of data at each level. The filter works in a hierarchical manner with several levels of detail using a coarse-to-fine approach. These filtered data were interpolated in two steps to a DTM raster of cell size $0.1 \mathrm{~m} \times 0.1 \mathrm{~m}$ with publicly available modules of the software Orientation and Processing of Airborne Laser Scanning data (OPALS) $[45,46]$. These two interpolation steps consist of a fine and a smoothed DTM. For the former, the minimum elevation value was assigned to each cell of size $0.1 \mathrm{~m}$. This results in an accurate DTM with remaining holes in empty cells. Therefore, the latter DTM interpolates the point cloud data to a smoothed model. The interpolation settings were set to a search radius of $1 \mathrm{~m}$ with 80 neighboring points. This second smoothed model was used to fill holes in the more accurate minimum DTM, as proposed by Siart et al. [47]. One hundred fifty-one reference points captured with an RTK GNSS rover were compared to the final DTM to assess its elevation accuracy.

\subsubsection{Registering Multitemporal TLS Data}

The data from each campaign were merged into one reference point cloud project. The scan position per campaign was registered to locate each scan position into a common coordinate system using a master position based on the coordinates of the scanner and two tie point reflectors. Thereafter, all other scan positions were registered to this master position by translating and rotating them until the smallest distance, on average, among all tie point pairs was reached. The master position as well as tie point reflectors were chosen according to the simulated ATLS set-up. This means that the scan position representing that of all subsequent campaigns $\left(t_{2}-t_{8}\right)$ was used as the master position and the positions of two reflectors were used to register each subsequent campaign $\left(t_{2}-t_{8}\right)$. The position of the two reflectors did not change during the entire study since they were mounted on permanently installed metal poles for each campaign.

After this coarse registration, an iterative closest point algorithm (ICP) implemented in the multi-station adjustment (MSA) of RiSCAN Pro was applied. To improve the coarse registration, the MSA detects planes that are common in different scans as polydata planes. Then the ICP algorithm [48] is employed at the center of these planes to find translation and rotation matrices that minimize the distance between them [31]. As for the MSA, the point clouds are translated and rotated based on unchanged surfaces of polydata planes resulting in a fine-registered (i.e., georeferenced) dataset. In this study, position and orientation of the first measurement were locked and further measurements were adjusted to this fixed position. The study area was then extracted from the registered data and exported as an ASCII file containing XYZ coordinates and the timestamp per point for further point density reduction. This workflow is similar to Tilly et al. $[38,49,50]$. 


\subsubsection{Point Density Reduction}

In order to reduce point density, every $n^{\text {th }}$ emitted laser beam was kept according to its timestamp, with increasing step widths $n$ as proposed by Hämmerle et al. [4]. Investigated step widths range from $n=0$ to $n=50$ at increments of 2. Analogous to Hämmerle et al. [4], low-resolution scans were captured as a reference for artificially reduced point density. Those low-resolution scans were captured with $0.6 \mathrm{mrad}, 1.2 \mathrm{mrad}, 5 \mathrm{mrad}$ and $8 \mathrm{mrad}$ (i.e., point spacing of $6 \mathrm{~mm}, 12 \mathrm{~mm}, 50 \mathrm{~mm}$ and $80 \mathrm{~mm}$ at $10 \mathrm{~m}$ distance) for each measurement campaign. Thereby, the step width can be set in relation to a corresponding resolution.

\subsubsection{Crop Height Modeling}

A raster of a cell size of $0.25 \mathrm{~m} \times 0.25 \mathrm{~m}$ using the maximum $z$ value per cell was created as a CSM per campaign. Thereafter, the difference between this maximum raster and the DTM was calculated as CHM per campaign. If the difference is negative, the CSM value lies under the DTM value, which indicates that the interpolated DTM cell lies above the actual surface. Such cells were filled with no value in the resulting CHM and were not interpolated as in other studies [14,27]. If the difference was positive, its height value was assigned to the cell. However, if the value exceeded the maximum height of $3 \mathrm{~m}$ [51], the cell was also filled with no value. This filtered out unrealistically high values, which might occur due to reflection from particles or insects in the air. Such vertical outliers were not removed manually as in $[4,50]$ since this would contradict the idea of simulating an autonomously operating and processing system. These steps were automatically repeated for all point clouds of reduced point density ranging from step width $n=0$ to $n=50$. The entire workflow is based on OPALS modules automatically executable in a Python script.

\subsection{Accuracy Assessment of Crop Height Models}

As for CHM accuracy assessment, the manually measured height at 140 unchanging reference plants was compared to corresponding $\mathrm{CHM}$ cell values. If a reference plant was within a $\mathrm{CHM}$ cell, the difference between CHM height and the manually measured height of the reference plant was captured as $\Delta h$. Factors influencing $\Delta h$ were statistically investigated by calculating Pearson's coefficient of determination $\left(R^{2}\right)$ between $\Delta h$ and distance to the scanner as well as between $\Delta h$ and point density. This information helps to decide on parameters such as distance to scanner and point density when constructing an ATLS set-up for crop height measurements. When $\Delta h$ needed to be averaged, median $\Delta h$ was used, since it is less susceptible to distortion by outliers than mean $\Delta h$.

\subsubsection{Point Density Effects}

TLS data from each campaign were reduced with step widths ranging from $n=0$ to $n=50$ at increments of 2, as described in Section 2.2.3. This resulted in a systematic reduction of point density. To analyze the effect of this reduction on CHM accuracy, $\Delta h$ values of a CHM from one campaign were averaged and investigated per step width $n$. This shows to what extent the accuracy of a CHM is influenced by point density in correspondence to the crop height. Furthermore, $\Delta h$ values for all campaigns per step width were averaged. This indicates the overall influence of a reduced point density on CHMs and allows the conduction of specific requirements for designing an ATLS.

\subsubsection{Distance to Scanner Effects}

In order to analyze the influence of an increasing distance to the scanner and CHM accuracy, the distance between the scanner and each reference plant as well as $\Delta h$ were calculated for each position and each campaign. The distance was based on the known coordinates of the scanner and the reference plants captured with RTK GNSS. The distances between these points were calculated as the Euclidean distance between two coordinates in 3D. Thereafter, $\Delta h$ values extracted from CHMs of different point densities were analyzed for each reference plant. 


\section{Results}

In the following the results of $\mathrm{CHM}$ generation and CHM accuracy assessment are presented. The structure corresponds to that of the methods described in the previous section.

\subsection{Generation of Crop Height Models}

After registering multitemporal TLS data from eight point clouds $\left(t_{1}-t_{8}\right)$, the difference of coordinate pairs in all scans varies $0.001 \mathrm{~m}(x),-0.001 \mathrm{~m}(y)$ and $0.024 \mathrm{~m}(z)$, on average. Each of these eight point clouds encompasses $16,689,483$ points, on average. While the first reduction step $(n=2)$ leads to a reduction of about $50 \%(7,388,193$ points $)$ of the original point cloud, the final reduction step $(n=50)$ leads to a reduction of $98 \%$ (333,773 points). All point clouds resulting from step widths $n>10$ result in a reduction between $2 \%$ and $10 \%$ due to the exponential course shown in Figure 4 . The point count, on average, of low-resolution reference scans of $0.6 \mathrm{mrad}, 1.2 \mathrm{mrad}, 5 \mathrm{mrad}$ and $8 \mathrm{mrad}$ (i.e., point spacing of $6 \mathrm{~mm}, 12 \mathrm{~mm}, 50 \mathrm{~mm}$ and $80 \mathrm{~mm}$ at $10 \mathrm{~m}$ distance, respectively) with their corresponding point count is additionally shown in Figure 4.

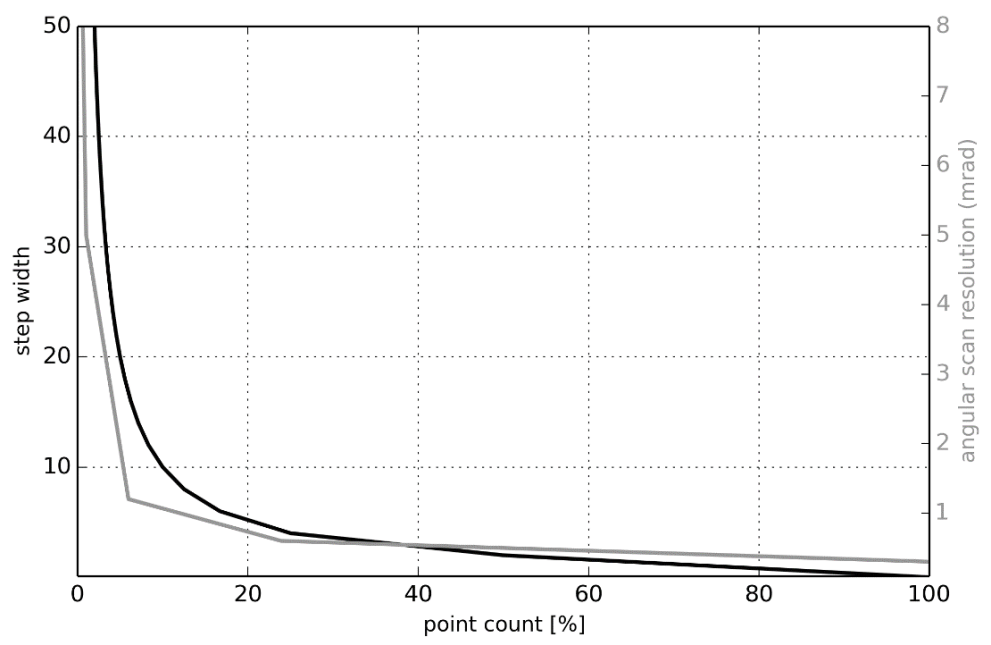

Figure 4. Influence of technically reduced scan resolution (mrad) and artificially increased step width on point density following approximately the same course of $\frac{1}{n}$.

CHMs are created for each campaign and data reduced with step width $n=0$ to $n=50$, where $n=0$ means that data remain unreduced and $n=50$ that data are reduced to $98 \%$. To exemplify such CHMs, Figure 5 shows CHMs for campaigns $t_{1}, t_{4}$ and $t_{8}$ based on unreduced data $(n=0)$.

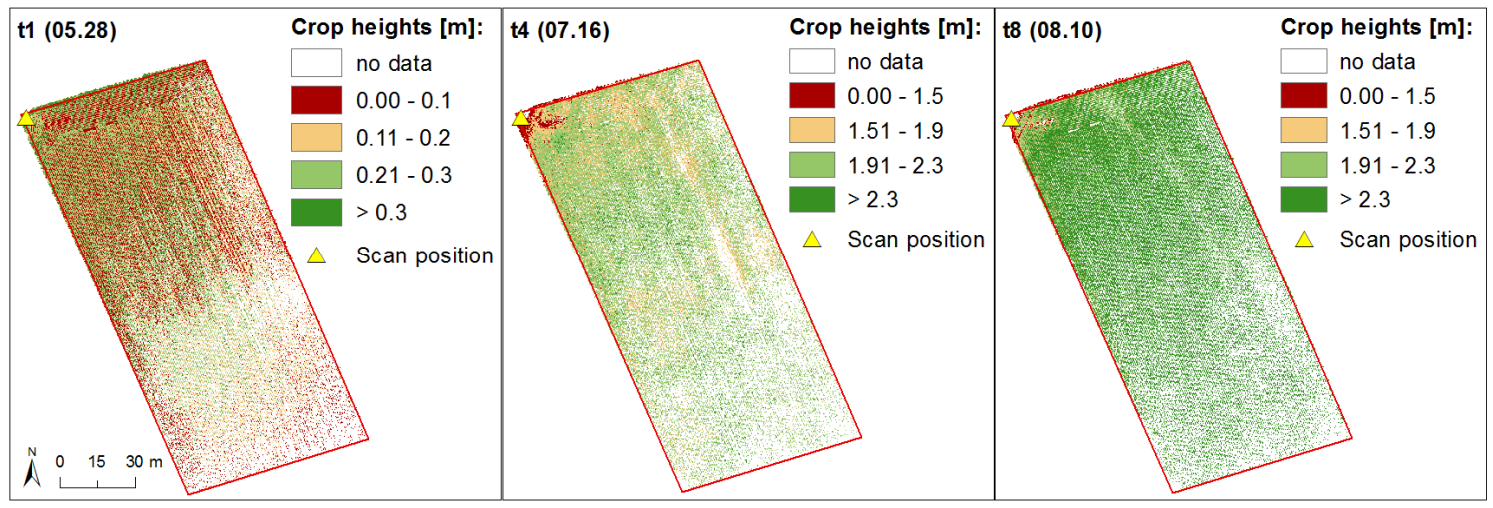

Figure 5. CHMs $\left(n=0\right.$, i.e., no artificial reduction) for $t_{1}, t_{4}$ and $t_{8}$ showing crop heights per $0.25 \mathrm{~m} \times 0.25 \mathrm{~m}$ cell. 


\subsection{Accuracy Assessment of Crop Height Models}

\subsubsection{Point Density Effects}

The decrease in point density leads to an increase in empty cells based on all campaigns. For $n=0$, on average, $47 \%$ of cells are empty with a point count, on average, of 77 points per $0.25 \mathrm{~m} \times 0.25 \mathrm{~m}$ cell. For $n=50$, on average, $85 \%$ of cells are empty with a point count, on average, of 2 points per $0.25 \mathrm{~m} \times 0.25 \mathrm{~m}$ cell. The point count decreases with increasing distance to the scanner as is shown for the second campaign $t_{2}$ (Figure 6). This distribution is similar for the other campaigns.

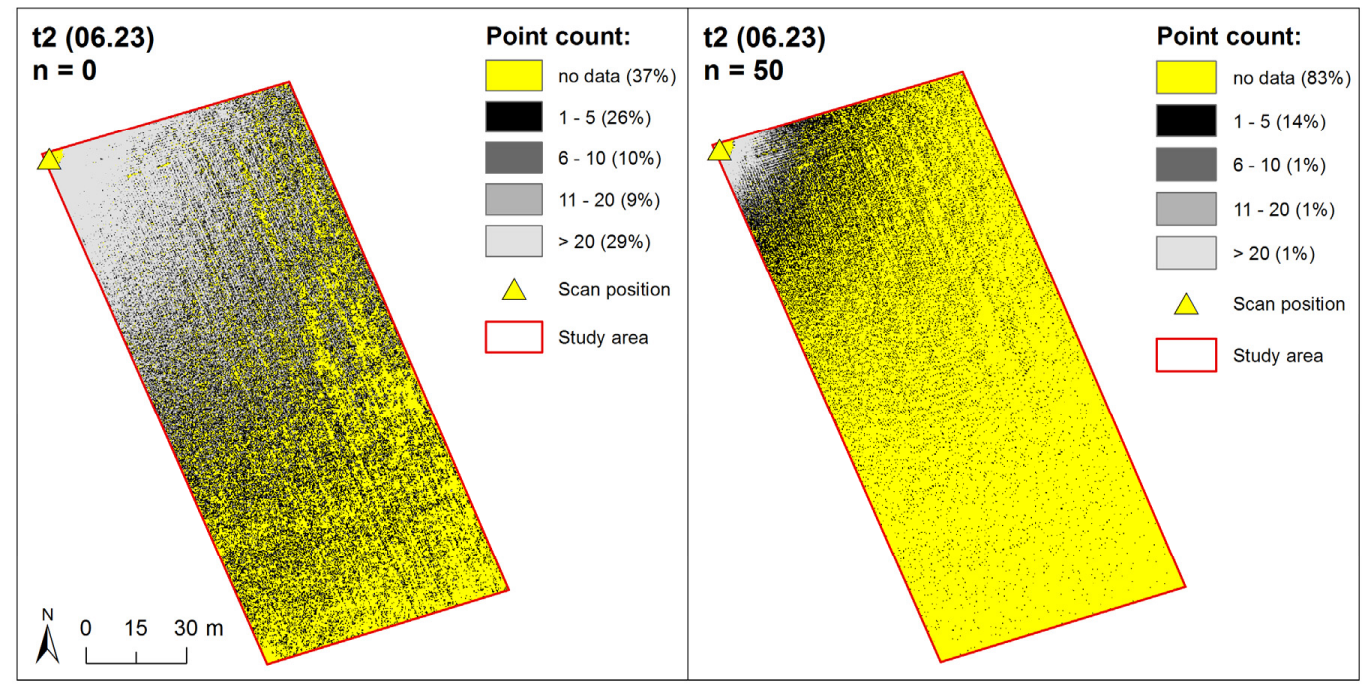

Figure 6. Spatial distribution of point count per $0.25 \mathrm{~m} \times 0.25 \mathrm{~m}$ cell used for CHM generation based on unreduced data ((left) step width $n=0)$ and maximally reduced data with $2 \%$ of original data remaining ((right) step width $n=50)$.

Calculated heights in CHMs are close to those manually measured regardless of point density reduction until approximately 95 days after seeding and a crop height of $2.3 \mathrm{~m}$ (Figure 7). CHMs represent the actual crop height in the most accurate way based on data reduced with step width $n=0$ (i.e., no artificial reduction) followed by $n=10$ (10\% of data remaining) and $n=50(2 \%$ of data remaining). The unreduced dataset $(n=0)$ leads to the smallest difference between manually measured reference plants and CHM based crop heights. This indicates that this unreduced point cloud includes rare points representing the top of the plant, whereas point clouds of reduced point density $(n=10$ and $n=50$ ) include ubiquitous points representing lower parts of the plant. This must be considered in the scan setting design for ATLS. When rasterizing such an unreduced point cloud to a CHM, the resulting CHM has higher crop height values, on average, than that of reduced point density. The number of reference plants used is given, since $\Delta h$, analyzed in the following, is only calculated if a $\mathrm{CHM}$ cell contains a value at the location of the reference plant.

In Figure 8, the course of $\Delta h$ for the CHMs derived from reduced point clouds with step width $n=0$ (unreduced) to $n=50$ (maximally reduced) is graphed. This relation was investigated for three campaigns $\left(t_{1}, t_{5}\right.$, and $\left.t_{8}\right)$. Table A1 in the Appendix provides detailed results for CHM accuracy assessment for each campaign and step widths $n=0, n=10$ and $n=50$. Figure 8 shows that a reduction of point density leads to a decrease in accuracy of CHM. The increase in $\Delta h$ with increasing step width is stronger for later campaigns. This is indicated by the increase in the slope value for the regression line. Another difference between campaigns is that $\Delta h$ increases with increasing crop height. This can be concluded from graphs of later measurements, which have most $\Delta h$ values above those of previous measurements. The linear dependence $R^{2}$ between $\Delta h$ and point density is similar for all campaigns 
$\left(\mathrm{t}_{1}=0.79, \mathrm{t}_{2}=0.80, \mathrm{t}_{3}=0.66, \mathrm{t}_{4}=0.78, \mathrm{t}_{5}=0.72, \mathrm{t}_{6}=0.82, \mathrm{t}_{7}=0.82, \mathrm{t}_{8}=0.82\right)$ and amounts to 0.78 on average. This indicates that an increase in $\Delta h$ can be correlated to an increase in step width and thereby a decrease in point density. In order to derive general statements about a required minimum point density, averaged $\Delta h$ values for all measurements are shown in Figure 8 . This value increases about $0.1 \mathrm{~m}$ in total, starting at approximately $0.02 \mathrm{~m}(n=0)$ and ending at $0.12 \mathrm{~m}(n=50)$. Similarly, the root mean square error (RMSE) of $\Delta h$ increases about $0.06 \mathrm{~m}$ in total, starting at approximately $0.16 \mathrm{~m}$ $(n=0)$ and ending at $0.22 \mathrm{~m}(n=50)$. The standard deviation of $\Delta h$ increases about $0.04 \mathrm{~m}$ in total, starting at approximately $0.15 \mathrm{~m}(n=0)$ and ending at $0.19 \mathrm{~m}(n=50)$.

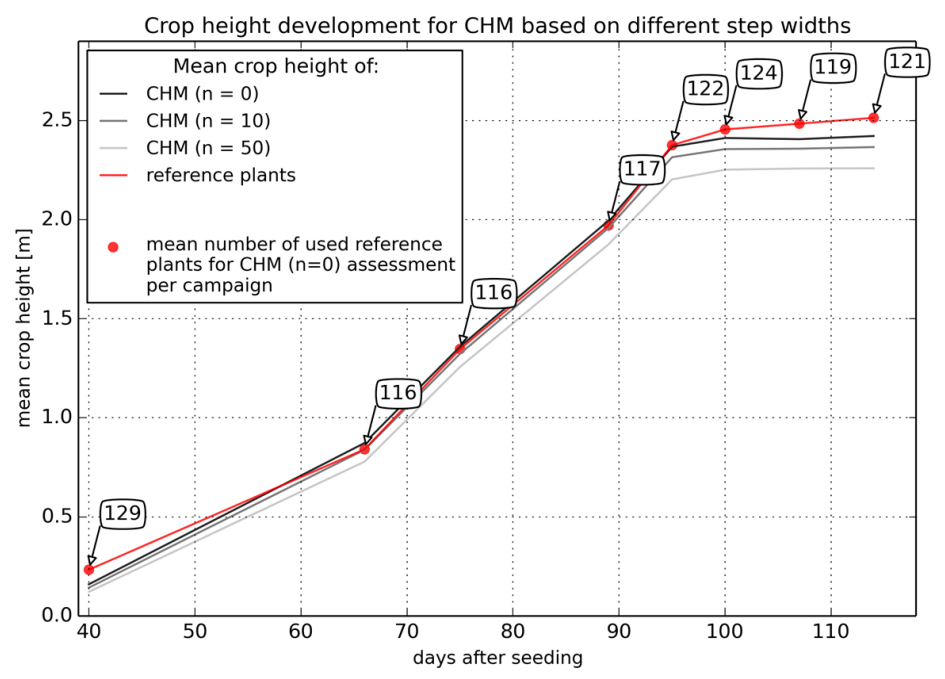

Figure 7. Crop height development based on CHMs for step width $n=0$ (i.e., no artificial reduction), $n=10$ (10\% of data remaining) and $n=50$ ( $2 \%$ of data remaining) and on manually measured reference plants. Connecting lines do not indicate linear crop growth.

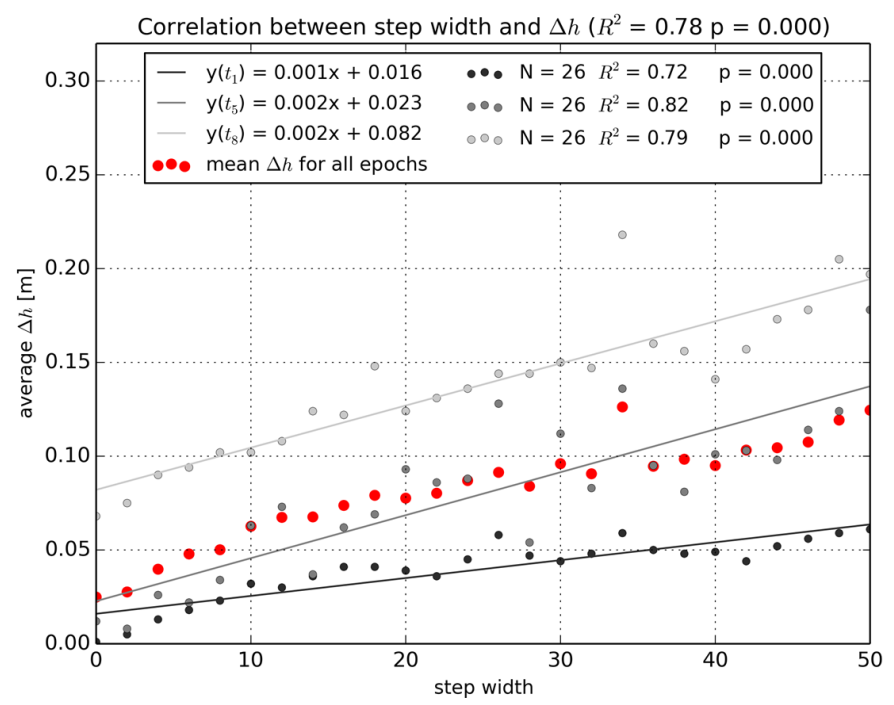

Figure 8. Accuracy of CHM at $40\left(\mathrm{t}_{1}\right), 95\left(\mathrm{t}_{5}\right)$ and $114\left(\mathrm{t}_{8}\right)$ days after seeding based on point clouds reduced with different step widths ( $n=0$, i.e., no artificial reduction, to $n=50$, i.e., $2 \%$ of data remaining). The points belonging to a specific campaign show $\Delta h$ averaged per step width and are summarized in a line of regression in the same color (y). Each campaign encompasses $26 \Delta h$ values, i.e., one for each step width from $n=0$ to $n=50$ at increments of 2. Pearson's coefficient of determination $\left(R^{2}\right)$ and $p$ value $(p)$ are additionally added. $R^{2}$ and $p$ averaged for all campaigns are shown in the figure title. 


\subsubsection{Distance to Scanner Effects}

Figure 9 represents the correlation between $\Delta h$ and the distance to scanner exemplified for $t_{3}$ and $t_{8}$. This correlation was investigated for unreduced CHMs ( $n=0$, i.e., no artificial reduction) and maximally reduced $\mathrm{CHMs}(n=50$, i.e., $2 \%$ of data remaining). Each point represents a reference plant for which a distance to the scanner and $\Delta h$ are calculated. The number of reference plants used for CHM assessment is indicated as $N$. The $R^{2}$ is calculated on all values per campaign and measures how well the regression line represents the data. The indicated mean crop height is calculated for unreduced data $(n=0)$.
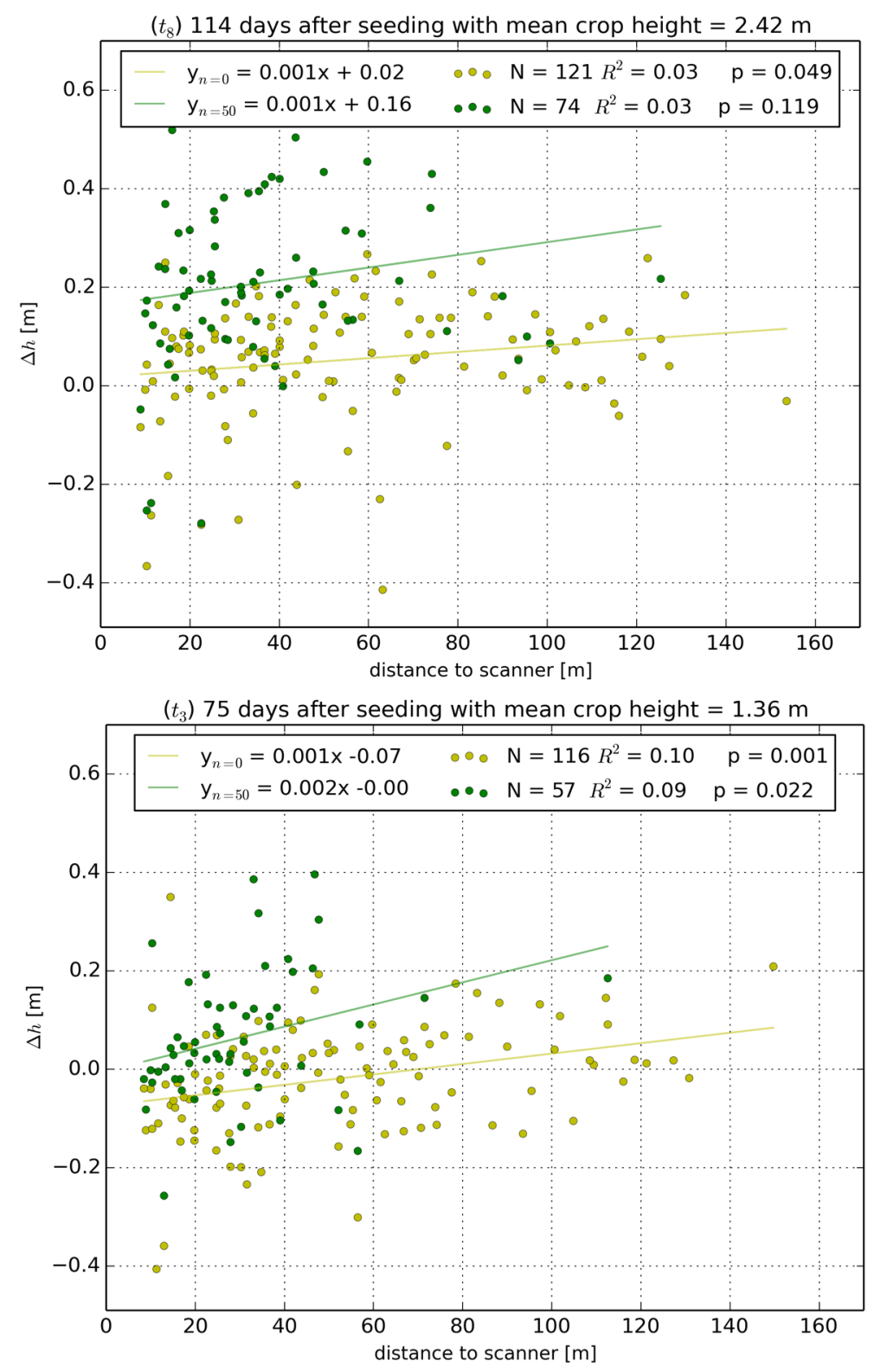

Figure 9. Relation between $\Delta h$ and distance to scanner for two campaigns ( $t_{3}$ and $\left.t_{8}\right)$ regarding line of regression $(y)$, number of reference plants used $(N)$, Pearson's coefficient of determination $\left(R^{2}\right)$ and $p$ value $(p)$ for CHMs based on $n=0$ (i.e., no artificial reduction) and $n=50$ (i.e., $2 \%$ of data remaining).

Figure 9 implies that $\Delta h$ values increasingly scatter with increasing crop height. Subsequently, $\mathrm{CHM}$ becomes less accurate with increasing crop height. Positive values of $\Delta h$ occur when the manually measured height has a higher value than the corresponding CHM cell. This is the case when the highest 
point in the point cloud at the position of the reference plant is beneath the reference plant. This might suggest that the highest point for that cell was not captured by the scanner due to occlusion effects or a scan resolution leading to gaps between laser beams. If a reference plant stands in such a gap, it will not be captured by the scanner. Negative values of $\Delta h$ imply that CHM leads to height values above those manually captured for the reference plants. They can be explained by the circumstance that starting at a certain crop height, the scanner might no longer be able to detect small plants within the field due to occlusion effects. With a scanner set-up from an elevated position of $3.6 \mathrm{~m}$, occlusion effects possibly influence CHM accuracy. Such occlusion effects could prevent capturing small plants especially with increasing distance to the scanner.

The $R^{2}$ for all campaigns amounts to 0.06 on average based on data for $n=0$ (i.e., no artificial reduction) and 0.04 for $n=50$ (i.e., $2 \%$ of data remaining). Due to fewer empty cells, more reference plants are used for CHM accuracy assessment for $n=0$ (mean $=121$ plants) than for $n=50$ (mean $=66$ plants). Mostly plants located further away from the scanner are no longer used for CHM accuracy assessment for $n=50$, since point count, and thereby the number of cells containing data, decreases with increasing distance to the scanner (Figure 6). Considering the maximum distance between the reference plants and the scanner, statements about CHM accuracy can only be made up to a distance of $150 \mathrm{~m}$ for CHMs based on step width $n=0$ and of $100 \mathrm{~m}$ for CHMs based on $n=50$. For these distances, no linear dependence between $\Delta h$ and distance to scanner could be deduced.

\section{Discussion}

\subsection{Study Area and Measurement Set-Up}

The non-invasive measurement set-up, which performed the monitoring from one field edge at a height of $3.6 \mathrm{~m}$, eliminated the need to physically enter the field. This is a major asset, increasing the usability of LiDAR technology in precision agriculture as Mulla [21] and Tilly et al. [38] also concluded. At the same time, the elevated scan position compensated for unfavorable scan geometry due to a low viewing angle similarly constructed by Eltner et al. [52]. The scan position in this study was stable over time and practical for conducting the scan campaigns. The elevated scanner set-up was similarly employed in other studies. Tilly et al. scanned from a position $3 \mathrm{~m}$ above ground [38] as well as $4 \mathrm{~m}$ above ground [50]. Analogously, Hämmerle et al. [4] mounted the scanner on a platform elevated $4 \mathrm{~m}$ above ground. Eitel et al. [40] noted the necessity of multiple ATLS when monitoring highly dynamic 3D ecosystem processes changing on a minute or hourly basis. A set-up of multiple TLS systems was employed by Tilly et al. [38]. The level of accuracy reached in our studies can be obtained when using one single static position at a height of $3.6 \mathrm{~m}$. For CHM accuracy the measurement set-up should be at least $3.6 \mathrm{~m}$ for crops reaching a maximum height of approximately $2.8 \mathrm{~m}$, as shown.

One limitation of this study is its limited ability to simulate the beam divergence of a low-cost scanning system. The system's beam divergence will generally be larger for laser rangefinders of ATLS systems than that of the scanner used in this study $(0.3 \mathrm{mrad})$. The first ATLS system employed by Eitel et al. [40] applied a laser rangefinder with a divergence of $4.5 \mathrm{mrad}$. This beam divergence has a high impact on data accuracy, but is not investigated by simulating a reduced angular scan resolution as done in this study. The influence of beam divergence remains to be examined when designing an ATLS system consisting of a laser rangefinder with a low scan resolution. In order to reduce the influence of scanning geometry and beam divergence [28,53], a radiometric calibration for a static TLS might be considered as investigated in other studies [26,54].

Finally, the study bears minor limitations in terms of its reference data. Comparing heights of single plants against rasterized cell values results in reference plants not being used if one reference plant is located above a CHM cell containing no data. Furthermore, reference plants were selected randomly and thus might not be truly representative for the entire field. As mentioned by McGrew et al. [55], randomness does not guarantee an unbiased sample, since other sources of sampling errors are possible. In particular, the accuracy of CHM cells in the southeast corner of the 
study area, where no reference plants are located, cannot thoroughly be assessed. Selection of the highest point above the maximum height per reference plant proved to be challenging. Hager et al. propose measuring from the soil surface to the arch of the uppermost leaf that has emerged more than $50 \%$ of its full size [56]. However, such heights would not be usable as a reference for CHMs based on maximum height values. Moreover, measuring the specific value from the measuring tape becomes difficult when the plant exceeds $2 \mathrm{~m}$. For an observer of average body height $(1.70 \mathrm{~m})$, plant heights of $2.70 \mathrm{~m}$ and above are difficult to measure when standing on the ground. Despite these minor limitations, the procedure seems most feasible for this investigation and led to valuable results.

\subsection{Generation of Crop Height Models}

As for the fine-registration of multitemporal TLS data, the plane patch filter used, should be employed on areas that remain unchanged for all campaigns. It might not be possible to find stable and plane areas in a field with growing crops that can be used for ICP and thus fine-registration. In this case, it might be considered to manually set-up plane areas such as a wooden pallet. In this study, the mean deviation for all measurements in $x, y$ and $z$ direction of $0.01 \mathrm{~m}$ is similarly low as obtained by Tilly et al. $(0.06 \mathrm{~m}$ and $0.01 \mathrm{~m})$ for aligning multitemporal scans of rice crops [38] and $0.04 \mathrm{~m}$ for scans of barley crops [50].

In addition to the data accuracy, the subsequent point density reduction deserves closer attention. Overall, the parameter crop height seems to be robust against huge reductions of point density. These findings are similarly observed by Höfle [28] on maize crops in an early stage of growth. His findings show a high correctness (i.e., precision) and completeness (i.e., true positive rate) for plant detection even for data with highly reduced point density. He argues that a point density of about 100 points per $0.01 \mathrm{~m}^{2}$ is sufficient for detecting maize plants with a correctness of $90 \%$ and a completeness of $80 \%$. In this study, point density amounts to 308 points, on average, per $0.01 \mathrm{~m}^{2}$ for unreduced data $(n=0)$ and 8 points per $0.01 \mathrm{~m}^{2}$ for maximally reduced data $(n=50$, i.e., $2 \%$ of data remaining).

Our findings permit some general statements about the minimum ATLS point density needed for the monitoring of maize and structurally similar crops. As Hämmerle et al. [4] state, the scan resolution applied needs to be set in accordance to crop stand features such as crop type, fertilization stage, growth stage and required accuracy (which depends on fitness for use). Additionally, it has to be mentioned that the artificial reduction of point density simulates a low-cost ATLS system only to a certain extent. Hämmerle et al. [4] state that their method of keeping every $n^{\text {th }}$ laser beam to reduce point density represents a low-cost scan with limitations. High-resolution scans used as a basis for reducing point density have a high penetration rate. Subsequently, conducted point clouds of reduced point density encompass points of laser beams that would not have been captured in the case of a real low-resolution scan. Real low-resolution scans were not used in this study, since it was the study's objective to gain knowledge about reasonable resolution settings for an ATLS system. Using real low-resolution scans would have required this information.

\subsection{Accuracy Assessment of Crop Height Models}

Based on the findings of this study, the scan resolution can be reduced to $1 / 50$ ( $8 \mathrm{mrad}$ i.e., point spacing of $80 \mathrm{~mm}$ at $10 \mathrm{~m}$ distance) of the original resolution $(0.3 \mathrm{mrad})$, resulting in a point cloud encompassing $2 \%$ of the original number of points. This reduction leads to an increase of $0.1 \mathrm{~m}$ for $\Delta h$, on average, from $0.02 \mathrm{~m}$ to $0.12 \mathrm{~m}$. With RMSE of $\Delta h$ increasing $0.06 \mathrm{~m}$, it can be concluded that models and applications that use RMSE of $\Delta h$ are robust against reducing scanning resolution, as also stated by Hämmerle et al. [4]. This is especially true until 95 days after maize seeding, when CHM's accuracy remains essentially constant of point density reduction (Figure 7). CHM's accuracy measured via $\Delta h$ decreases for later measurements when crops are higher than $2.3 \mathrm{~m}$ (Figure 7), because occlusion effects appear more often. The scanner height should be chosen according to maximum crop height in order to optimize the accuracy. Therefore, the measurement set-up with a height of $3.6 \mathrm{~m}$ seems most feasible for crops not exceeding $2.3 \mathrm{~m}$. For crops reaching a maximum height of approximately 
$2.8 \mathrm{~m}$, such as the maize crops investigated in this study, the measurement set-up should be at least $3.6 \mathrm{~m}$ to reduce occlusion effects. Such effects could also be minimized when scanning crops that have a homogenous crop surface such as cereal or rice, as proposed by Hämmerle et al. [4]. Additionally, CHMs would be of more homogenous quality especially for circular fields when installing the ATLS in the middle of the field. Based on the findings, a maximum distance of $100 \mathrm{~m}$ between crops and scanners with a wavelength similar to the VZ-400 does not seem to influence CHM accuracy for $n=50$ $(150 \mathrm{~m}$ for $n=0)$.

\section{Conclusions and Outlook}

This study shows that LiDAR technology in general and multitemporal 3D geodata in particular are feasible for application in precision agriculture. A reduction of $90 \%(n=10)$ of the original point cloud results in an accuracy of $0.06 \mathrm{~m}$ and a reduction of $98 \%(n=50)$ in an accuracy of $0.12 \mathrm{~m}$. The last reduction step corresponds to a scan resolution of $8 \mathrm{mrad}$, i.e., point spacing of $80 \mathrm{~mm}$ at $10 \mathrm{~m}$ distance. These results can be expected for a maximum distance of $100 \mathrm{~m}(150 \mathrm{~m}$ for $n=0$, i.e., no artificial reduction) between scanner and crops. For these distances, no correlation could be identified between distance and accuracy of the crop height model (CHM). One autonomously operating TLS (ATLS) with an angular resolution of $8 \mathrm{mrad}$, i.e., point spacing of $80 \mathrm{~mm}$ at $10 \mathrm{~m}$ distance should suffice when aiming to capture crop heights from a field not exceeding $100 \mathrm{~m}$ in length or radius.

A fixed ATLS position throughout the study period is essential for efficiency. This reduces time and work needed to transform and align each measurement within one common coordinate system. Similarly, tie point reflectors should ideally not move and should be placed at fixed locations with varying distances from the scanner. The set-up applied in this study together with the method developed for CHM generation should only be used for crops not exceeding $2.3 \mathrm{~m}$. Beyond this height, CHM accuracy decreases. Our workflow that automatically derives and assesses CHMs is reusable in a multitude of further studies and application scenarios. Analogously, it could be refined to process multitemporal 3D geodata for monitoring environmental changes (e.g., landslides, snow cover or glaciers).

An ATLS system as simulated in this study should scan with a regularity depending on growth rate and required $\mathrm{CHM}$ accuracy. With maize crops growing $0.03 \mathrm{~m}$ per day, on average, and an accuracy of $0.12 \mathrm{~m}$ for the simulated ATLS ( $n=50$, i.e., $2 \%$ of data remaining), the system could be employed once per week. As growth rates vary (Figure 7), scans should be captured more often 70 to 90 days after seeding. Starting from approximately 110 days after seeding, the investigated maize crop stopped increasing in height. Henceforth, fewer scans can be employed, since smaller changes will be detectable.

Basically, our results make it possible to think of a network of static low-cost sensors that can cover the most important and crucial parts of a crop stand. Thus, having a network of ATLS allows the monitoring of larger and specific areas of interest. This would also include "mobile" sensors that perform the scans from static location but can move between different locations. Thinking of a fully mobile system that scans during movement (e.g., tractor-mounted or mounted on unmanned aerial vehicles (UAV)) requires a completely different sensor system (integrating RTK, inertial measurement units (IMU), etc.) and thus also different/other experiments than we did. Further research could investigate the transferability of our approach by using a real low-cost laser scanning system as in $[40,41]$ based on the specific outcomes of this study. The transfer of our results to additional crops (e.g., wheat, rye or rice), crop parameters (e.g., plant volume or nutrient content) and different measurement set-ups (e.g., mobile vs. static) could be investigated to complement and enhance knowledge about the potential of a TLS in precision agriculture.

Acknowledgments: This research was performed within the research project " $4 \mathrm{D}$ Near Real-Time Environmental Monitoring (4DEMON)" funded by the Federal Ministry of Science, Research and Arts (MWK), Baden-Wuerttemberg. We would like to thank members of the LiDAR research group, in particular Martin Hämmerle, for helping during our fieldwork. In addition, we would like to thank Sabrina Marx for helping to 
register the point cloud data. Dirk Hoffmeister gave valuable feedback on key findings of this study. Furthermore, we extend our thanks to the Laboratory for Geomorphology and Geoecology of Heidelberg University for lending us the water barrel. Finally, we are grateful to Markus Wolf for providing his maize field as a study area. We acknowledge the financial support of the Deutsche Forschungsgemeinschaft (DFG) and Heidelberg University within the funding programme Open Access Publishing.

Author Contributions: Sophie Crommelinck collected and prepared all the data and carried out the analysis. Bernhard Höfle contributed to the analysis and interpretation of results. Additionally, he supervised the process of defining the study design and data acquisition. The manuscript was written by Sophie Crommelinck with contributions from Bernhard Höfle.

Conflicts of Interest: The authors declare no conflict of interest.

\section{Appendix}

Table A1. Detailed results for accuracy assessment for CHMs calculated for step widths $n=0$ (i.e., no artificial reduction) $n=10$ (i.e., $10 \%$ of data remaining) and $n=50$ (i.e., $2 \%$ of data remaining). RMSE refers to the root mean square error.

\begin{tabular}{|c|c|c|c|c|c|}
\hline $\begin{array}{l}\text { Campaign } \\
(t)\end{array}$ & $\begin{array}{c}\text { Step Width } \\
(n)\end{array}$ & $\begin{array}{l}\text { Reference Plants } \\
\text { Used (N) }\end{array}$ & $\begin{array}{l}\text { Mean } \Delta h \\
\quad(\mathrm{~m})\end{array}$ & $\begin{array}{c}\text { Median } \Delta h \\
\text { (m) }\end{array}$ & $\begin{array}{c}\text { RMSE of } \Delta h \\
\text { (m) }\end{array}$ \\
\hline \multirow{3}{*}{1} & 0 & 129 & 0.006 & 0.001 & 0.052 \\
\hline & 10 & 102 & 0.035 & 0.032 & 0.065 \\
\hline & 50 & 69 & 0.07 & 0.061 & 0.092 \\
\hline \multirow{3}{*}{2} & 0 & 116 & -0.03 & -0.027 & 0.084 \\
\hline & 10 & 99 & 0.006 & 0.007 & 0.103 \\
\hline & 50 & 62 & 0.07 & 0.044 & 0.146 \\
\hline \multirow{3}{*}{3} & 0 & 116 & -0.02 & -0.013 & 0.112 \\
\hline & 10 & 98 & 0.025 & 0.026 & 0.118 \\
\hline & 50 & 57 & 0.063 & 0.043 & 0.144 \\
\hline \multirow{3}{*}{4} & 0 & 117 & -0.023 & 0.019 & 0.227 \\
\hline & 10 & 91 & 0.005 & 0.038 & 0.218 \\
\hline & 50 & 68 & 0.080 & 0.094 & 0.238 \\
\hline \multirow{3}{*}{5} & 0 & 122 & -0.010 & 0.012 & 0.292 \\
\hline & 10 & 91 & 0.027 & 0.063 & 0.289 \\
\hline & 50 & 63 & 0.136 & 0.178 & 0.347 \\
\hline \multirow{3}{*}{6} & 0 & 124 & 0.024 & 0.067 & 0.195 \\
\hline & 10 & 99 & 0.068 & 0.12 & 0.216 \\
\hline & 50 & 65 & 0.126 & 0.172 & 0.269 \\
\hline \multirow{3}{*}{7} & 0 & 119 & 0.040 & 0.072 & 0.16 \\
\hline & 10 & 103 & 0.098 & 0.113 & 0.204 \\
\hline & 50 & 71 & 0.177 & 0.207 & 0.277 \\
\hline \multirow{3}{*}{8} & 0 & 121 & 0.053 & 0.068 & 0.132 \\
\hline & 10 & 100 & 0.097 & 0.102 & 0.163 \\
\hline & 50 & 74 & 0.211 & 0.197 & 0.271 \\
\hline
\end{tabular}

\section{References}

1. Lee, W.S.; Alchanatis, V.; Yang, C.; Hirafuji, M.; Moshou, D.; Li, C. Sensing technologies for precision specialty crop production. Comput. Electron. Agric. 2010, 74, 2-33. [CrossRef]

2. Rosell, J.R.; Llorens, J.; Sanz, R.; Arnó, J.; Ribes-Dasi, M.; Masip, J.; Escolà, A.; Camp, F.; Solanelles, F.; Gràcia, F.; et al. Obtaining the three-dimensional structure of tree orchards from remote 2D terrestrial LiDAR scanning. Agric. For. Meteorol. 2009, 149, 1505-1515. [CrossRef]

3. Zhang, N.; Wang, M.; Wang, N. Precision agriculture-A worldwide overview. Comput. Electron. Agric. 2002, 36, 113-132. [CrossRef] 
4. Hämmerle, M.; Höfle, B. Effects of reduced terrestrial lidar point density on high-resolution grain crop surface models in precision agriculture. Sensors 2014, 14, 24212-24230. [CrossRef] [PubMed]

5. Schellberg, J.; Hill, M.J.; Gerhards, R.; Rothmund, M.; Braun, M. Precision agriculture on grassland: Applications, perspectives and constraints. Eur. J. Agron. 2008, 29, 59-71. [CrossRef]

6. McCarthy, C.L.; Hancock, N.H.; Raine, S.R. Applied machine vision of plants: A review with implications for field deployment in automated farming operations. Intell. Serv. Robot. 2010, 3, 209-217. [CrossRef]

7. Giles, D.; Delwiche, M.; Dodd, R. Electronic measurement of tree canopy volume. Trans. ASAE 1988, 31, 264-272.

8. Zaman, Q.; Salyani, M. Effects of foliage density and ground speed on ultrasonic measurement of citrus tree volume. Appl. Eng. Agric. 2004, 20, 173-178. [CrossRef]

9. Schumann, A.W. Performance of an ultrasonic tree volume measurement system in commercial citrus groves. Precis. Agric. 2005, 6, 467-480.

10. Solanelles, F.; Escolà, A.; Planas, S.; Rosell, J.; Camp, F.; Gràcia, F. An electronic control system for pesticide application proportional to the canopy width of tree crops. Biosyst. Eng. 2006, 95, 473-481. [CrossRef]

11. Llorens, J.; Gil, E.; Llop, J. Ultrasonic and LiDAR sensors for electronic canopy characterization in vineyards: Advances to improve pesticide application methods. Sensors 2011, 11, 2177-2194. [CrossRef] [PubMed]

12. Phattaralerphong, J.; Sinoquet, H. A method for 3D reconstruction of tree crown volume from photographs: Assessment with 3D-digitized plants. Tree Physiol. 2005, 25, 1229-1242. [CrossRef] [PubMed]

13. Leblanc, S.G.; Chen, J.M.; Fernandes, R.; Deering, D.W.; Conley, A. Methodology comparison for canopy structure parameters extraction from digital hemispherical photography in boreal forests. Agric. For. Meteorol. 2005, 129, 187-207. [CrossRef]

14. Bendig, J.; Bolten, A.; Bennertz, S.; Broscheit, J.; Eichfuss, S.; Bareth, G. Estimating biomass of barley using crop surface models (CSMs) derived from UAV-based rgb imaging. Remote Sens. 2014, 6, 10395-10412. [CrossRef]

15. Andersen, H.J.; Reng, L.; Kirk, K. Geometric plant properties by relaxed stereo vision using simulated annealing. Comput. Electron. Agric. 2005, 49, 219-232. [CrossRef]

16. Kise, M.; Zhang, Q. Development of a stereovision sensing system for 3D crop row structure mapping and tractor guidance. Biosyst. Eng. 2008, 101, 191-198. [CrossRef]

17. Rovira-Más, F.; Zhang, Q.; Reid, J. Creation of three-dimensional crop maps based on aerial stereoimages. Biosyst. Eng. 2005, 90, 251-259. [CrossRef]

18. Bendig, J.; Bolten, A.; Bareth, G. Uav-based imaging for multi-temporal, very high resolution crop surface models to monitor crop growth variability. Photogramm. Fernerkund. Geoinfor. 2013, 2013, 551-562. [CrossRef]

19. Giuliani, R.; Magnanini, E.; Fragassa, C.; Nerozzi, F. Ground monitoring the light-shadow windows of a tree canopy to yield canopy light interception and morphological traits. Plant Cell Environ. 2000, 23, 783-796. [CrossRef]

20. Bongers, F. Methods to assess tropical rain forest canopy structure: An overview. Plant Ecol. 2001, 153, 263-277. [CrossRef]

21. Mulla, D.J. Twenty five years of remote sensing in precision agriculture: Key advances and remaining knowledge gaps. Biosyst. Eng. 2013, 114, 358-371. [CrossRef]

22. Stuppy, W.H.; Maisano, J.A.; Colbert, M.W.; Rudall, P.J.; Rowe, T.B. Three-dimensional analysis of plant structure using high-resolution X-ray computed tomography. Trends Plant Sci. 2003, 8, 2-6. [CrossRef]

23. Van der Zande, D.; Hoet, W.; Jonckheere, I.; van Aardt, J.; Coppin, P. Influence of measurement set-up of ground-based LiDAR for derivation of tree structure. Agric. For. Meteorol. 2006, 141, 147-160. [CrossRef]

24. Paulus, S.; Dupuis, J.; Riedel, S.; Kuhlmann, H. Automated analysis of barley organs using 3D laser scanning: An approach for high throughput phenotyping. Sensors 2014, 14, 12670-12686. [CrossRef] [PubMed]

25. Van der Heijden, G.; Song, Y.; Horgan, G.; Polder, G.; Dieleman, A.; Bink, M.; Palloix, A.; van Eeuwijk, F.; Glasbey, C. Spicy: Towards automated phenotyping of large pepper plants in the greenhouse. Funct. Plant Biol. 2012, 39, 870-877. [CrossRef]

26. König, K.; Höfle, B.; Hämmerle, M.; Jarmer, T.; Siegmann, B.; Lilienthal, H. Comparative classification analysis of post-harvest growth detection from terrestrial LiDAR point clouds in precision agriculture. ISPRS J. Photogramm. Remote Sens. 2015, 104, 112-125. [CrossRef]

27. Watt, P.J.; Donoghue, D.N.M. Measuring forest structure with terrestrial laser scanning. Int. J. Remote Sens. 2005, 26, 1437-1446. [CrossRef] 
28. Höfle, B. Radiometric correction of terrestrial LiDAR point cloud data for individual maize plant detection. IEEE Geosci. Remote Sens. Lett. 2014, 11, 94-98. [CrossRef]

29. Andujar, D.; Rueda-Ayala, V.; Moreno, H.; Rosell-Polo, J.R.; Escola, A.; Valero, C.; Gerhards, R.; Fernandez-Quintanilla, C.; Dorado, J.; Griepentrog, H.W. Discriminating crop, weeds and soil surface with a terrestrial LiDAR sensor. Sensors 2013, 13, 14662-14675. [CrossRef] [PubMed]

30. Paulus, S.; Schumann, H.; Kuhlmann, H.; Léon, J. High-precision laser scanning system for capturing 3D plant architecture and analysing growth of cereal plants. Biosyst. Eng. 2014, 121, 1-11. [CrossRef]

31. Hosoi, F.; Nakabayashi, K.; Omasa, K. 3-D modeling of tomato canopies using a high-resolution portable scanning LiDAR for extracting structural information. Sensors 2011, 11, 2166-2174. [CrossRef] [PubMed]

32. Sanz-Cortiella, R.; Llorens-Calveras, J.; Escola, A.; Arno-Satorra, J.; Ribes-Dasi, M.; Masip-Vilalta, J.; Camp, F.; Gracia-Aguila, F.; Solanelles-Batlle, F.; Planas-DeMarti, S.; et al. Innovative lidar 3D dynamic measurement system to estimate fruit-tree leaf area. Sensors 2011, 11, 5769-5791. [CrossRef] [PubMed]

33. Keightley, K.E.; Bawden, G.W. 3D volumetric modeling of grapevine biomass using tripod LiDAR. Comput. Electron. Agric. 2010, 74, 305-312. [CrossRef]

34. Zhang, L.; Grift, T.E. A LiDAR-based crop height measurement system for miscanthus giganteus. Comput. Electron. Agric. 2012, 85, 70-76. [CrossRef]

35. Ehlert, D.; Heisig, M.; Adamek, R. Suitability of a laser rangefinder to characterize winter wheat. Precis. Agric. 2010, 11, 650-663. [CrossRef]

36. Omasa, K.; Hosoi, F.; Konishi, A. 3D LiDAR imaging for detecting and understanding plant responses and canopy structure. J. Exp. Bot. 2007, 58, 881-898. [CrossRef] [PubMed]

37. Zub, H.W.; Arnoult, S.; Brancourt-Hulmel, M. Key traits for biomass production identified in different miscanthus species at two harvest dates. Biomass Bioenergy 2011, 35, 637-651. [CrossRef]

38. Tilly, N.; Hoffmeister, D.; Cao, Q.; Lenz-Wiedemann, V.; Miao, Y.; Bareth, G. Transferability of models for estimating paddy rice biomass from spatial plant height data. Agriculture 2015, 5, 538-560. [CrossRef]

39. Tilly, N.; Hoffmeister, D.; Schiedung, H.; Hütt, C.; Brands, J.; Bareth, G. Terrestrial laser scanning for plant height measurement and biomass estimation of maize. ISPRS Int. Arch. Photogramm. Remote Sens. Spat. Inf. Sci. 2014, 1, 181-187. [CrossRef]

40. Eitel, J.U.H.; Vierling, L.A.; Magney, T.S. A lightweight, low cost autonomously operating terrestrial laser scanner for quantifying and monitoring ecosystem structural dynamics. Agric. For. Meteorol. 2013, 180, 86-96. [CrossRef]

41. Culvenor, D.S.; Newnham, G.J.; Mellor, A.; Sims, N.C.; Haywood, A. Automated in-situ laser scanner for monitoring forest leaf area index. Sensors 2014, 14, 14994-15008. [CrossRef] [PubMed]

42. Hoffmeister, D.; Bolten, A.; Curdt, C.; Waldhoff, G.; Bareth, G. High-resolution crop surface models (CSM) and crop volume models (CVM) on field level by terrestrial laser scanning. In Proceedings of the Sixth International Symposium on Digital Earth, Bejing, China, 9-12 September 2009; p. 78400E.

43. Riegl vz-400 Data Sheet. Available online: http://www.riegl.com/uploads/tx_pxpriegldownloads/10_ DataSheet_VZ-400_2014-09-19.pdf (accessed on 20 May 2015).

44. Riscan Pro for Riegl 3D Laser Scanners. Available online: http://www.riegl.com/uploads/tx pxpriegldownloads/11_DataSheet_RiSCAN-PRO_2016-01-13_02.pdf (accessed on 24 January 2016).

45. Pfeifer, N.; Mandlburger, G.; Otepka, J.; Karel, W. Opals-A framework for airborne laser scanning data analysis. Comput., Environ. Urban Syst. 2014, 45, 125-136. [CrossRef]

46. Opals-Orientation and Processing of Airborne Laser Scanning Data. Available online: http://geo.tuwien. ac.at/opals/html/index.html (accessed on 19 August 2015).

47. Siart, C.; Forbriger, M.; Nowaczinski, E.; Hecht, S.; Höfle, B. Fusion of multi-resolution surface (terrestrial laser scanning) and subsurface geodata (ERT, SRT) for karst landform investigation and geomorphometric quantification. Earth Surf. Process. Landf. 2013, 38, 1135-1147. [CrossRef]

48. Besl, P.J.; McKay, N.D. Method for registration of 3-D shapes. In Robotics-DL Tentative; International Society for Optics and Photonics: Boston, MA, USA, 1992; pp. 586-606.

49. Tilly, N.; Hoffmeister, D.; Cao, Q.; Huang, S.; Lenz-Wiedemann, V.; Miao, Y.; Bareth, G. Multitemporal crop surface models: Accurate plant height measurement and biomass estimation with terrestrial laser scanning in paddy rice. J. Appl. Remote Sens. 2014, 8, 083671. [CrossRef]

50. Tilly, N.; Aasen, H.; Bareth, G. Fusion of plant height and vegetation indices for the estimation of barley biomass. Remote Sens. 2015, 7, 11449-11480. [CrossRef] 
51. Edwards, J. Maize Growth and Development. Available online: http://dpi.nsw.gov.au/_data/assets / pdf_file/0007/516184/Procrop-maize-growth-and-development.pdf (assessed on 26 February 2016).

52. Eltner, A.; Baumgart, P. Accuracy constraints of terrestrial LiDAR data for soil erosion measurement: Application to a mediterranean field plot. Geomorphology 2015, 245, 243-254. [CrossRef]

53. Kaasalainen, S.; Jaakkola, A.; Kaasalainen, M.; Krooks, A.; Kukko, A. Analysis of incidence angle and distance effects on terrestrial laser scanner intensity: Search for correction methods. Remote Sens. 2011, 3, 2207-2221. [CrossRef]

54. Kaasalainen, S.; Krooks, A.; Kukko, A.; Kaartinen, H. Radiometric calibration of terrestrial laser scanners with external reference targets. Remote Sens. 2009, 1, 144-158. [CrossRef]

55. McGrew, J.C.; Monroe, C.B. An Introduction to Statistical Problem Solving in Geography; Waveland Press: New York, NY, USA, 2009.

56. Hager, A., Jr.; Sprague, C. Corn Stage Is Critical for Postemergence Herbicide Applications. Available online: http:/ / bulletin.ipm.illinois.edu/pastpest/articles/200210d.html (accessed on 26 May 2015).

(C) 2016 by the authors; licensee MDPI, Basel, Switzerland. This article is an open access article distributed under the terms and conditions of the Creative Commons by Attribution (CC-BY) license (http://creativecommons.org/licenses/by/4.0/). 